\title{
Post-Traumatic Right Diaphragmatic Hernia with Hepatothorax
}

\author{
Elias Amorim¹, Frederico Berniz Aragão², Armando Veiga², Alexandre Porto Galdez² \\ ${ }^{1}$ Head of Thoracic Surgery Service of the Maranhense Medical Center, São Luís, Brazil \\ ${ }^{2}$ Thoracic Surgeon of Maranhense Medical Center, São Luís, Brazil \\ Email: amorimelm@gmail.com
}

How to cite this paper: Amorim, E., Aragão, F.B., Veiga, A. and Galdez, A.P. (2018) Post-Traumatic Right Diaphragmatic Hernia with Hepatothorax. Open Journal of Thoracic Surgery, 8, 1-5. https://doi.org/10.4236/ojts.2018.81001

Received: January 15, 2018

Accepted: March 11, 2018

Published: March 14, 2018

Copyright ( 92018 by authors and Scientific Research Publishing Inc. This work is licensed under the Creative Commons Attribution International License (CC BY 4.0).

http://creativecommons.org/licenses/by/4.0/

(c) (i) Open Access

\begin{abstract}
Introduction: Traumatic right diaphragmatic hernia is an extremely rare entity, given the protection afforded by the liver. Clinical Case: A 51-year-old women who suffered a road-traffic accident presented with a heavy sensation and several episodes of moderate pain in the left hemithorax. Physical and radiological exams revealed a traumatic right hernia. Discussion: The diagnosis of hernia should be established as quickly as possible to reduce morbidity and mortality. Treatment of the injury is always surgical and outcome is invariably positive. Conclusion: The diagnosis of diaphragmatic hernia should always be considered in patients suffering road-traffic accidents to allow early diagnosis and successful treatment.
\end{abstract}

\section{Keywords}

Traumatic Diaphragmatic Hernia, Thoracic Surgery, Traumatology, Hepatothorax

\section{Introduction}

Traumatic injuries were first mentioned by Sennertus in 1541. In 1579, Ambrósio Paré reported a blunt trauma case. In 1853, Bodwicht established the first diagnosis of blunt left thoracic trauma. Riof (1886) and Walter (1889) successfully treated a hernia [1] [2].

Diaphragmatic injury due to trauma is a rare entity that is hard to diagnose, leading to delayed treatment and increased morbidity [3].

Abdominal hernia is a rare consequence of thoraco-abdominal trauma. Herniation of the right side of the diaphragm is an extremely rare condition owing to protection by the liver. Acute presentation is often life-threatening and early diagnosis is critical [4] [5]. 
Diaphragmatic hernia can also be caused by a defect in the diaphragm and is divided into congenital and acquired forms, where the latter may be confounded with Morgagni hernia. Traumatic right-sided hernia occurs in $0.8 \%-3.6 \%$ of blunt trauma cases [6] [7].

Diaphragmatic rupture is an uncommon condition, and in $80 \%$ of cases occurs to the left side. However, the incidence of rupture to the right side has risen due to an increase in road-traffic accidents [8] [9].

\section{Case Report}

A 55-year-old patient from the interior of Maranhão state, with a history of motor vehicle accident 7 years prior, was admitted to the Emergency Service presenting with fractures of the left ribs, grazes to the hemithorax on the same side and abdominal cavity depression.

The patient presented mild dyspnea on exertion and complained of hemithorax pain.

Results of blood work-up were within normal parameters.

A computed tomography scan was performed, disclosing the presence of condensation in the right hemithorax (Figure 1).

Surgery via the $6^{\text {th }}$ intercostal space was elected.

A lesion extending from the hemidiaphragm to anterior lateral rib cage with diaphragm detachment from the chest wall was observed. The whole of the liver had herniated into the chest wall with a twist leaving the upper part of the organ facing upwards, exposing the gallbladder (Figure 2).

After returning the liver into the abdominal cavity, the diaphragm was sutured using simple prolene 2 - 0 sutures. Subsequently, the diaphragm was reinserted into the rib cage.

Only a small amount of blood had accumulated within the abdominal cavity,

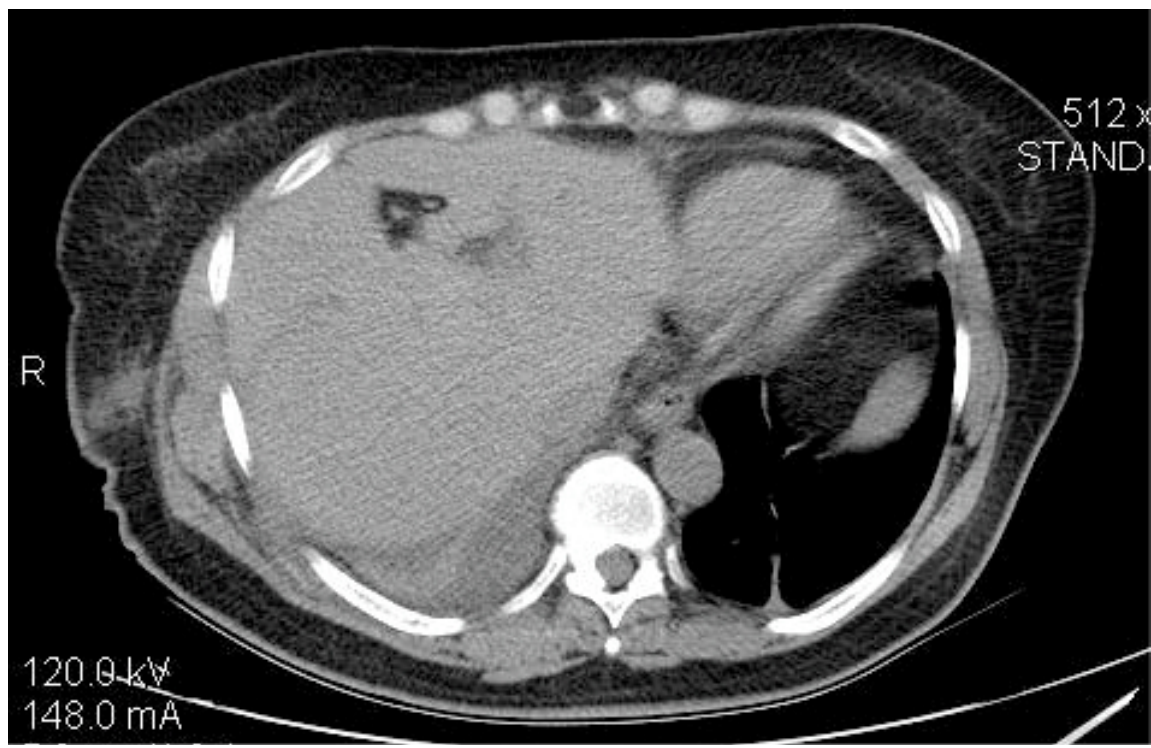

Figure 1. TC showing the liver inside the thorax. 


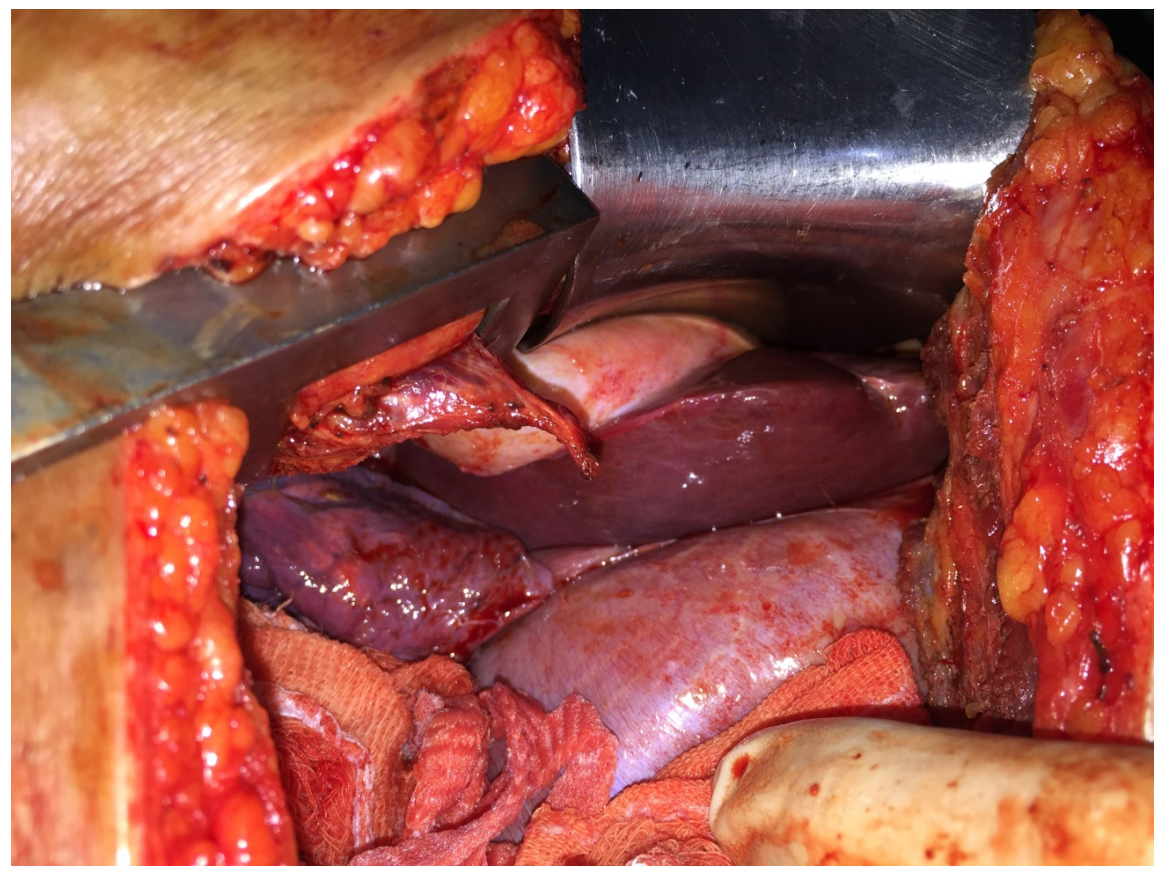

Figure 2. Surgery showing the liver rotational movement inside the thorax.

and no active bleeding was evident.

Pleural cavity drainage was performed using a 28 drain and the chest wall was closed, respecting anatomical planes.

The patient was discharged after the $6^{\text {th }}$ post-operative day and is under out-patient monitoring without abnormalities.

\section{Discussion}

Rupture of the diaphragm is a rare abdominal and thoracic complication found in $1 \%-5 \%$ of blunt trauma and $10 \%-15 \%$ of penetrating trauma cases. The case reported involved blunt trauma [10].

Rupture of the left hemidiaphragm is more common, but has increased owing to road-traffic accidents [9].

Herniation of the liver can become progressive, causing atelectasis of the right lung, leading to compromised expiratory status and hemodynamic instability [11]. In the present case, lung compression and dyspnea on exertion were observed, a situation which can rapidly evolve to hemodynamic instability.

Involvement of the right side is rare, because of protection by the liver, accounting for $5 \%-19 \%$ of all traumatic diaphragm ruptures. In the case reported, the injury was secondary to a major impact which the liver was unable to sustain [12].

Herniation of the abdominal structures into the chest cavity is often due to congenital defects, but in this case was caused by the major impact of the trauma [7] [8].

In this type of injury, rupture of the left hemidiaphragm occurs in $1 \%-12 \%$, as seen in the case described. 
Diaphragmatic hernia typically involves three phases: initial phase, at time of trauma; delayed phase, when herniation takes place (asymptomatic); and the obstructive phase, when the patient presents complication of the hernia, such as obstruction, strangulation and later rupture. These three stages were not observed in the present case, only pain from the trauma [6].

The high morbidity and mortality associated with this situation calls for early diagnosis and rapid treatment.

\section{Conclusions}

Although traumatic right diaphragmatic hernia is extremely rare, particularly in children, given the absence of specific clinical signs, it should always be considered [12] [13] in thoraco-abdominal trauma patients, and should not be neglected in emergency services.

Chest computed-tomography scan is the exam of choice in cases of traumatic diaphragmatic hernia.

\section{Funding}

No conflicts of interest.

\section{References}

[1] Sosa, G.G., Nogueiras, M.C. and Rodrigues, S.A.C. (2013) Right Traumatic Diaphragmatic Hérnia. Revista Cubana de Cirugía, 52, 324-331.

[2] Shah, R., Sabanathan, S., Mearns, A.J. and Choudhury, A.K. (1995) Traumatic Rupture of Diaphragm. The Annals of Thoracic Surgery, 60, 1444-1449. https://doi.org/10.1016/0003-4975(95)00629-Y

[3] Pedro, J., Brasileiro, L., Lopes, V.G.P. and Fonseca, O.C.L. (2016) Right Diaphragmatic Hepatotorax with Earl Surgical Correction. Gastroenterologia e Endoscopia Digestiva, 35, 155-157.

[4] Sala, C., Bonaldi, M., Mariani, P. and Novellino, L. (2017) Right Post-Traumatic Diaphragmatic Hérnia with Liver and Intestinal Dislocation. Journal of Surgical Case Reports, 2017, 1-3. https://doi.org/10.1093/jscr/rjw220

[5] Das, S., Zirpe, D., Gopakumar, C.V., Swain, S.K. and Surendran, R. (2016) Asymptomatic Hepatothorax, Symptomatic Gall Stone Disease-A Rare Coincidence. Journal of Clinical and Diagnostic Research, 10, 1-4.

[6] Atif, Q.A.I. and Khaliq, T. (2016) Traumatic Right Diaphragmatic Hernia; A Delayed Presentation. Journal of Ayub Medical College Abbottabad, 28, 625-626.

[7] Amorim, E. and Pacheco, J.S. (2004) Mogagni Hernia Simulatina a THORACIC lipomatous Tumor. Revista do Colégio Brasileiro de Cirurgióes, 31, 398-399. https://doi.org/10.1590/S0100-69912004000600012

[8] Sahin, A., Artas, H. and Yalniz, M. (2017) A Rare Cause of Right-Sided Air Bubble on Chest Radiograph: Intrathoracic Gastric Volvulus Related Do Morgagni Hernia. Case Reports in Gastroenterology, 11, 103-108. https://doi.org/10.1159/000457790

[9] Monteiro, M.T.R.V.L., Pereira, L. and Seco, C. (2016) Chronic Hepatotorax Due to Right Diaphragm Rupture: An Anesthetic Challenge in a Rare Case. Brazilian Journal of Anesthesiology, 68, 190-193. https://doi.org/10.1016/j.bjane.2015.08.010

[10] Quadradozzi, F., Favoriti, P., Favoriti, M. and Cofini, G. (2016) Anusual Repair in a 
Rare Case of Hepatotorax Due to Right-Sided Diaphragmatic Rupture: A Case Report. Il Giornale di Chirurgia, 37, 84-85.

[11] Parreira, J.M., Chibata, M., Skinovsky, J., Martins, A.M. and Schmidt, F.R. (2009) Diaphragmatic Hernia Late Right Associated with Hepatothorax-Literature Review. Arquivos Brasileiros de Cirurgia Digestiva, 22, 183-185. https://doi.org/10.1590/S0102-67202009000300010

[12] Sala, G., Bonaldi, M., Mariani, P., Tagliabue, F. and Novelino, L. (2017) Right Post-Traumatic Diaphragmatic Hernia with Liver and Intestinal Deslocation. Journal of Surgical Case Report, 3, 1-2.

[13] Ndour, O., Mustapha, H., Ndoye, N.A., Fall, A.L.F., Ngom, G. and Ndoye, M. (2015) Traumatic Right Diaphragmatic Hernia in Children: Diagnostic Difficulties. African Journal of Paediatric Surgery, 12, 94-97.

https://doi.org/10.4103/0189-6725.151004 